\title{
Reference normal values and design of a vision screening for 4 to 5 years old preschoolers
}

\section{Diseño de un screening visual y valores normales de referencia para preescolares con edad entre 4 y 5 años}

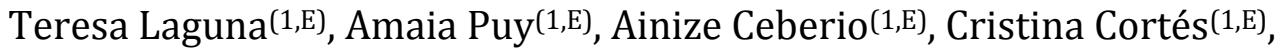 \\ Ana Sánchez-Cano ${ }^{\left(1,2, S,{ }^{*}\right)}$, Sebastián Jarabo(1,S) \\ 1. Department of Applied Physics. University of Zaragoza, Zaragoza, Spain. \\ 2. IIS Aragon, Aragon Health Sciences Institute, Zaragoza, Spain. \\ (*) Email: anaisa@unizar.es $\quad$ S: miembro de SEDOPTICA / SEDOPTICA member \\ Received / Recibido: 06/06/2014. Revised / Revisado: 08/07/2014. Accepted / Aceptado: 09/07/2014. \\ DOI: http://dx.doi.org/10.7149/OPA.47.3.197
}

\begin{abstract}
:
A vision screening program for preschool children of 4-5 years old was designed and analyzed. Information of the prevalence of ocular conditions among preschool children was obtained. The vision health of a group of 127 children was evaluated by a comprehensive examination in their own school. If a child failed one or more screening tests, he was referred to the ophthalmologist. Of the children screened in this study, $61 \%$ passed distance visual acuity and retinoscopy tests, $17 \%$ were referred to the ophthalmologist and $22 \%$ will be annually monitoring. Values of monocular/binocular acuity worse than $0.5 / 0.6$ are too poor for 4 years old children, whereas these limits increase up to $0.6 / 0.8$ for 5 years old children. In conclusion, the prevalence of undetected vision problems in preschool children has been clearly demonstrated. Vision screening programs in schools are highly recommended. Nevertheless, coordination among professionals conducting screening, school personnel and parents are needed to reach high levels of success. The results of this study validate an easy and fast battery of tests. The vision screening has been highly reliable because reference normal values have been defined by analyzing statistically the results of these tests.
\end{abstract}

Key words: Vision Screening, Pre-School Health, Optics Education.

\section{RESUMEN:}

Se diseñó y analizó un screening visual en preescolares de 4-5 años de edad. Se obtuvo información de la prevalencia de las condiciones oculares entre estos preescolares. Se evaluó la salud visual de un grupo de 127 niños con un examen completo en su propia escuela. Si el niño fallaba uno o más test era referido al oftalmólogo. De los niños revisados en el estudio, el $61 \%$ superó los test de agudeza visual y retinoscopía, al $17 \%$ se le refirió al oftalmólogo y el $22 \%$ será controlado anualmente. Valores de agudeza monocular/binocular peores de 0.5/0.6 son demasiado bajos para niños de 4 años de edad, mientras que estos límites se incrementan a 0.6/0.8 para niños de 5 años. En conclusión, la prevalencia de problemas de visión sin detectar en niños preescolares ha sido claramente demostrada. Sin embargo, es necesaria la coordinación entre profesionales que realicen el screening, personal del colegio y padres para alcanzar niveles altos de éxito. Los resultados de este estudio validan una batería rápida de test. El screening visual ha sido altamente fiable porque los valores normales de referencia han sido definidos analizando estadísticamente los resultados de estos tests.

Palabras clave: Screening Visual, Salud Preescolar, Educación en Óptica.

\footnotetext{
E During the development of the work, coauthors T. Laguna, A. Puy, A. Ceberio, and C. Cortés were students of the Optics and Optometry Grade of the University of Zaragoza (Spain).
} 


\section{REFERENCES AND LINKS / REFERENCIAS Y ENLACES}

[1]. A. H. Cohen, S. Lieberman, M. Stolzberg, J. M. Ritty, "The NYSOA vision screening battery: A total approach", J. Am. Optom. Assoc. 54, 979-984 (1983).

[2]. S. Lehmkuhle, R. P. Garzia, L. Turner, T. Hash, J. A. Baro, "A defective visual pathway in children with reading disability", New Engl. J. Med. 328, 989-996 (1993). DOI

[3]. I. Krumholtz, "Results from a pediatric vision screening and its ability to predict academic performance", Optometry 71, 426-430 (2000).

[4[. M. M. Shovman, M. Ahissar, "Isolating the impact of visual perception on dyslexics' reading ability", Vision Res. 46, 3514-3525 (2006). DOI

[5]. W. Dusek, B. K. Pierscionek, J. F. McClelland, "A survey of visual function in an Austrian population of school-age children with reading and writing difficulties", BMC Ophthalmol. 10, 16 (2010). DOI

[6]. M. I. Bodack, I. Chung, I. Krumholtz, "An analysis of vision screening data from New York City public schools", Optometry 81, 476-484 (2010). DOI

[7]. W. L. Marsh-Tootle, D. A. Corliss, S. L. Alvarez, K. A. Clore, K. M. Daum, A. Gordon, G. Houston, F. F. Perry, M. W. Swanson, "A statistical analysis of modified clinical technique vision screening of preschoolers by optometry students", Optometry Vision Sci. 71, 593-603 (1994). DOI

[8]. E. C. Marshall, R. E. Meetz, L. L. Harmon, "Through our children's eyes: The public health impact of the vision screening requirements for Indiana school children", Optometry 81, 71-82 (2010). DOI

[9]. I. Krumholtz, "Results of a vision screening program: An initial study", J. Am. Optom. Assoc. 66, 608612 (1995).

[10]. M. W. Preslan, A. Novak, "Baltimore vision screening project. Phase 2", Ophthalmology 105, 150-153 (1998). DOI

[11]. L. Pizzarello, M. Tilp, L. Tiezzi, R: Vaughn, J. McCarthy, "A new school-based program to provide eyeglasses: Childsight", J. AAPOS 2, 372-374 (1998). DOI

[12]. J. N. Zaba, R. A. Johnson, W. T. Reynolds, "Vision examinations for all children entering public school the new Kentucky law", Optometry 74, 149-158 (2003).

[13]. R. N. Kleinstein, L. A. Jones, S. Hullett, S. Kwon, R. J. Lee, N. E. Friedman, R. E. Manny, D. O. Mutti, J. A. Yu, K. Zadnik, "Refractive error and ethnicity in children", Arch. Ophthalmol. 121, 1141-1147 (2003). DOI

[14]. N. S. Anstice, B. Thompson, "The measurement of visual acuity in children: an evidence-based update", Clin. Exp. Optom. 97, 3-11 (2014). DOI

[15].S. Hopkins, G. P. Sampson, P. Hendicott, J. M. Wood, "Review of guidelines for children's vision screenings", Clin. Exp. Optom. 96, 443-449 (2013). DOI

[16]. N. Pastorino, Y. Penerini, "Programa de detección de déficit de la agudeza visual en escolares sin patología ocular aparente", Archivos Argentinos de Pediatría (Buenos Aires) 96, 236 (1996).

[17].V. H. Hu, A. Starling, S. N. Baynham, H. Wager, G. A. Shun-Shin, "Accuracy of referrals from an orthoptic vision screening program for 3- to 4-year-old preschool children", J AAPOS 16, 49-52 (2012). DOI

[18]. D. K. Newman, A. Hitchcock, H. McCarthy, J. Keast-Butler, A. T. Moore, "Preschool vision screening: outcome of children referred to the hospital eye service", Brit. J. Ophthalmol. 80, 1077-1082 (1996). DOI

[19]. C. E. Basch, "Vision and the achievement gap among urban minority youth", J. School Health 81, 599605 (2011). DOI

[20]. B. Robinson, W. R. Bobier, E. Martin, L. Bryant, "Measurement of the validity of a preschool vision screening program", Am. J. Public Health 89, 193-198 (1999). DOI

[21]. R. H. Duckman, Visual Development, Diagnosis, and Treatment of the Pediatric Patient, Philadelphia: Lippincott Williams \& Wilkins (2006).

[22]. A. S. Pai, K. A. Rose, C. Samarawickrama, R. Fotedar, G. Burlutsky, R. Varma, P. Mitchell, "Testability of refraction, stereopsis, and other ocular measures in preschool children: The Sydney paediatric eye disease study", J. AAPOS 16, 185-192 (2012). DOI 
[23]. K. Tarczy-Hornoch, J. Lin, J. Deneen, S. A. Cotter, S. P. Azen, M. S. Borchert, Y. Wang, R. Varma, T. Barak, J. Chang, J. Diaz, A. Foong, J. Gardner, G. Martinez, R. McKean, K. Milo, C. Moya, A. Penate, A. Reiner, C. Salazar, E. Song, M. Torres, N. Uribe, A. Zhu, C. Kwong, N. Noedel, M. Preciado, K. Tucke, "Stereoacuity testability in African-American and Hispanic pre-school children”, Optometry Vision Sci. 85, 158-163. (2008). DOI

[24].G. J. Hayes, B. E. Cohen, M. W. Rouse, P. N. De Land, "Normative values for the nearpoint of convergence of elementary schoolchildren", Optometry Vision Sci. 75, 506-512 (1998). DOI

[25]. M. Scheiman, M. Gallaway, K. A. Frantz, R. J. Peters, S. Hatch, M. Cuff, G. L. Mitchell, "Nearpoint of convergence: test procedure, target selection, and normative data", Optometry Vision Sci. 80, 214-225 (2003). DOI

[26]. W. C. Maples, R. Hoenes, "Near point of convergence norms measured in elementary school children", Optometry Vision Sci. 84, 224-228 (2007). DOI

[27]. R. M. Ingram, W. W. Holland, C. Walker, J. M. Wilson, P. E. Arnold, S. Dally, "Screening for visual defects in preschool children", Brit. J. Ophthalmol. 70, 16-21 (1986). DOI

[28]. A. R. Kemper, A. Helfrich, J. Talbot, N. Patel, "Outcomes of an elementary school-based vision screening program in North Carolina”, J. Sch. Nurs. 28, 24-30 (2012). DOI

[29]. S. P. Donahue, B. Arthur, D. E. Neely, R. W. Arnold, D. Silbert, J. B. Ruben, "Guidelines for automated preschool vision screening: A 10-year, evidence-based update", J. AAPOS 17, 4-8 (2013). DOI

[30]. R. P. Wormald, "Preschool vision screening in Cornwall: Performance indicators of community orthoptists", Arch. Dis. Child. 66, 917-920 (1991). DOI

[31]. P. Schmidt, M. Maguire, V. Dobson, G. Quinn, E. Ciner, L. Cyert, M. Taylor-Kulp, B. Moore, D. OrelBixler, E. Peskin, M. Redford, J. Schultz, "Comparison of preschool vision screening tests as administered by licensed eye care professionals in the vision in preschoolers study", Ophthalmology 111, 637-650 (2004). DOI

[32]. L. Tong, S. M. Saw, E. S. Chan, M. Yap, H. Y. Lee, Y. P. Kwang, D. Tan, "Screening for myopia and refractive errors using LogMAR visual acuity by optometrists and a simplified visual acuity chart by nurses", Optometry Vision Sci. 81, 684-691 (2004). DOI

[33].V. Dobson, "Preschool vision screening tests administered by nurse screeners compared with lay screeners in the vision in preschoolers study", Invest. Ophth. Vis. Sci. 46, 2639-2648 (2005). DOI

[34]. L. Ore, H. J. Garzozi, A. Tamir, N. Stein, M. Cohen-Dar, "Performance measures of the illiterate E-chart vision-screening test used in Northern District Israeli school children", J. Med. Screen. 15, 65-71 (2008). DOI

[35]. K. Tarczy-Hornoch, R. Varma, S. A. Cotter, R. McKean-Cowdin, J. H. Lin, M. S. Borchert, M. Torres, G. Wen, S. P. Azen, J. M. Tielsch, D. S. Friedman, M. X. Repka, J. Katz, J. Ibironke, L. Giordano, "Risk factors for decreased visual acuity in preschool children: the multi-ethnic pediatric eye disease and Baltimore pediatric eye disease studies", Ophthalmology 118, 2262-2273 (2011). DOI

[36]. L. O'Donoghue, J. F. McClelland, N. S. Logan, A. R. Rudnicka, C. G. Owen, K. J. Saunders, "Refractive error and visual impairment in school children in Northern Ireland", Brit. J. Ophthalmol. 94, 11551159 (2010). DOI

[37]. L. O'Donoghue, A. R. Rudnicka, J. F. McClelland, N. S. Logan, K. J. Saunders, "Visual acuity measures do not reliably detect childhood refractive error: An epidemiological study", PLoS One 7, e34441 (2012). DOI

[38].V. Dobson, J. M. Miller, C. E. Clifford-Donaldson, E. M. Harvey, “Associations between anisometropia, amblyopia, and reduced stereoacuity in a school-aged population with a high prevalence of astigmatism", Invest. Ophth. Vis. Sci. 49, 4427-4436 (2008). DOI

[39]. L. O'Donoghue, A. R. Rudnicka, J. F. McClelland, N. S. Logan, C. G. Owen, K. J. Saunders, "Refractive and corneal astigmatism in white school children in northern Ireland", Invest. Ophth. Vis. Sci. 52, 40484053 (2011). DOI

[40]. J. A. Greenwood, V. K. Tailor, J. J. Sloper, A. J. Simmers, P. J. Bex, S. C. Dakin, "Visual acuity, crowding, and stereo-vision are linked in children with and without amblyopia", Invest. Ophth. Vis. Sci. 53, 76557665 (2012). DOI 
[41]. G. S. Ying, J. Huang, M. G. Maguire, G. Quinn, M. T. Kulp, E. Ciner, L. Cyert, D. Orel-Bixler, “Associations of anisometropia with unilateral amblyopia, interocular acuity difference, and stereoacuity in preschoolers", Ophthalmology 120, 495-503 (2013). DOI

\section{Introduction}

As it is well-known, undetected and uncorrected refractive error or vision problems are usual in preschool-age children, and they may adversely affect student performance and interfere with the learning process [1-5]. Early detection of these visual defects allows timely interventions in the form of spectacle correction or orthoptic cares. Thus, visual defects could be corrected as soon as possible and their negative consequences could be mitigated and even suppressed. In the case of preschool and schoolage children a vision screening adapted to these children is an essential preventive method $[1,6]$.

First of all, a vision screening has to be highly reliable. That is to say, only those children who have visual problems will fail the screening and will be referred to the ophthalmologist [6-8]. Moreover, as children pay attention during a short time (twenty minutes), the vision screening should be fast enough to avoid fatigue them, but also quite complete, since it is necessary to check any visual defect. Nevertheless, there is always taken into account that the screening test itself does not diagnose.

In order to design a screening with these features, appropriate protocols must be defined. Some studies have previously described screenings of children of different ethnicity, range of age or vision abnormalities with diverse statistical results [6,9-16]. Although the election of suitable tests is very important, a screening will have success if reference values in function of the children age are well defined. The key of an efficient screening is to balance the referral criteria so that both the over-referrals and under-referrals are minimized [6,15,17]. This point has created controversy among professionals, particularly in terms of the referral criteria used. In fact, although vision screening is a recommended component of routine preventive care for children, the rate and quality of screening in primary care settings is inconsistent. Referral rates to the ophthalmologist and vision problems documented are influenced by the conditions and strategies of the screenings $[15,17,18]$.

Childhood visual defects have been widely studied. However, it is quite difficult to find reference values in the literature, since only some few papers include statistical studies $[6,14,16,19]$. Therefore, it results very useful to analyze the values obtained in any screening to check and improve the next screening. Of course, it would be necessary to carry out a higher number of studies in order to have current values in function of age, sex, ethnic group, geographical location and socio-economic class.

Generally speaking, schools provide an excellent opportunity to reach a very high number of children of all ethnicities, lifestyles or customs and to establish normal visual values for all of them. Unfortunately, vision screening tests based only on distance visual acuity (VA) are still one of the most widely used in schools despite of the fact that less than half of the children with clinically significant visual disorders were identified by distance VA alone [20]. In fact, screening only for distance VA may miss those children with hyperopia, binocular disorders or other ocular health problems. Therefore, binocular function tests and retinoscopy should be incorporated in these screenings.

Although ophthalmologists play the main role in the diagnosis and treatment of eye diseases and pathological disorders of vision, optometrists are those professionals that are trained and educated to perform a complete examination of the visual performance of an individual. In Spain, one lack of this health profession is that optometrists may not use diagnosis drugs to make those visual examinations requiring an accommodation paralysis. Nevertheless, optometrists are fully trained to perform any visual screening including, visual acuities, objective refraction, or binocular vision tests to conclude the type of ammetropy and binocular problem that may occur. 
A screening with high reliability and validity can be difficult to control in a school due to the conditions of the setting. A vision screening program for public schools was developed and carried out by professors and students of the last year of the Optics and Optometry Degree in the University of Zaragoza. The specific objectives of the present study were (1) to design and evaluate a complete method of visual screening and (2) to analyze the results of this screening in scholar children. Such information may be important to formulate ocular health strategies and to establish the suitable age of the children to detect specific visual impairments. This kind of optometric initiative makes children, parents, teachers, and school personnel aware of the visual health.

\section{Methods}

\subsection{Participants}

A total of 129 children (55 females and 74 males), 4 years old (32 children; 15 females and 17 males) or 5 years old ( 97 children; 40 females and 57 males) were recruited in two schools of Zaragoza (Spain) to participate during fall and winter of the 2012-2013 academic year in this study. Schools were contacted notifying the schools' teachers about the study and face-toface meeting were conducted with the director and the research staff. A detailed description of the screening was sent to all parents or legal guardians of children. Of the 172 families who received the information, $75 \%$ accepted. Parents were informed about the screening results and a more exhaustive ophthalmological examination was advised if the child had failed the screening. The research adhered to the tenets of the Declaration of Helsinki and parents or legal guardians of children provided written informed consent.

\subsection{Instruments and procedure}

Each child was subject to a detailed optometric examination, which was formed by the following tests, in this order $(3,6,9)$ : distance VA (by using Snellen or Lea Symbol chart), near VA (by means of broken wheels chart), retinoscopy (without cyclopegic and by employing skiascope lenses), cover testing for near, near point of convergence
(NPC), ocular motility, near Worth four dots, stereoscopic acuity (Titmus-Wirt) and color vision tests (Ishihara).

Tests were conducted in rooms that provided a standard environment with minimal distractions and optimal physical conditions. Retinoscopy protocol necessitates a higher degree of training, skill and clinical knowledge. Optometry students were tutored by two professors (optometrist and physicist) while they were testing at least four children.

If the child was wearing glasses all tests were performed with glasses on. The average time for each student to complete the screening was around 20 minutes, appropriate time for 4 to 5 years old children. The decision to refer for follow-up care was based on failure of one or more tests of the screening battery.

\subsection{Data analysis}

Screening results were transferred and stored for data management and analysis to our own database. Statistical analysis was made with Microsoft Excel ${ }^{\circledR} \quad$ (Microsoft Corporation) calculating mean values and percentage of children belonging to each category. Histograms were used as graphical representation of the distribution of the data.

\section{Results}

A total of 129 children were screening although only 127 of them completed the battery.

\subsection{Distance VA}

Children were tested for monocular and binocular distance VA with Snellen or Lea Symbol charts depending on their ability to respond. The chart was placed to a distance of 3 $\mathrm{m}$ to hold the child's attention during the test. Acuities were recorded in decimal values and classified in several categories $(<0.5,0.5,0.6,0.8$, and $\geq 1$ ) in order to analyze their statistical distribution in function of gender and age of the children. Results do not have any dependence on gender, however, the statistical distribution of the VA presents appreciable changes with the age of the children. Growth in ocular structures occurs before 6 years of age, looking for the 


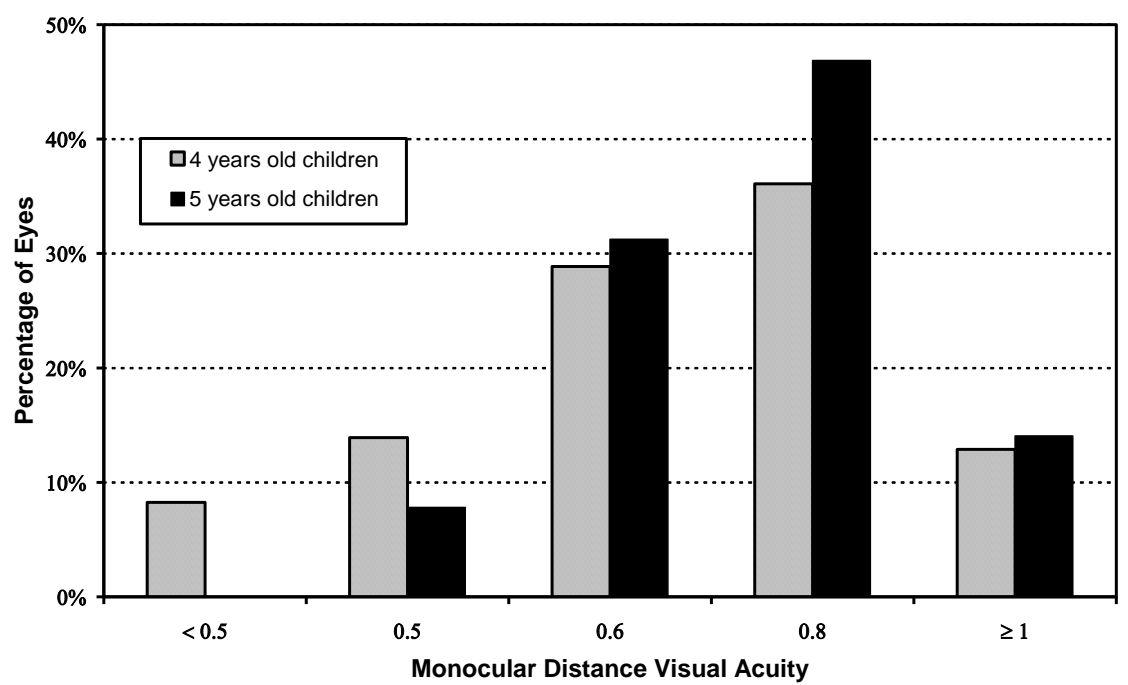

Fig. 1. Statistical distribution of monocular distance visual acuity.

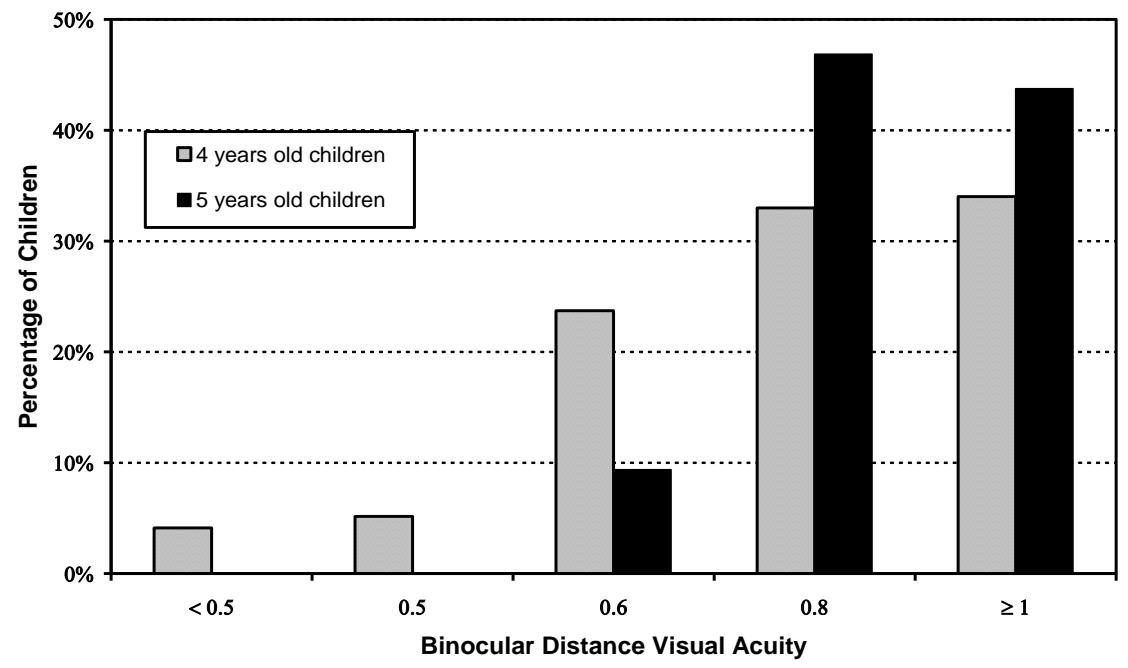

Fig. 2. Statistical distribution of binocular distance visual acuity.

emmetropization, after which elongation slows with age. Younger children usually are more hyperopic than older children and low astigmatic refraction is hoped being found. Depending of the test used, the age of the evaluated children and of their cognitive development different best visual acuity is reached. The older the children are the higher levels of this parameter they achieve. Children aged 5 have monocular and binocular distance VA better than 4 years old children, as it can be seen in Figs. 1 and 2.

In order to establish a failure criterion, accumulative percentages are computed and shown in Figs. 3 and 4 . Values of monocular/binocular acuity worse than 0.5/0.6 can be considered too poor for 4 years old children, whereas these limits can be increased up to $0.6 / 0.8$ for 5 years old children $[16,21]$.

\subsection{Near VA}

The broken wheels chart was employed to check monocular and binocular near VA. This test was not useful to distinguish visual problems since it was passed $(\mathrm{VA}=1)$ by all of them, except one

child (VA=0.4) that failed also other tests. Nevertheless, this result was expected because the children of theses ages usually have a high accommodation power. 


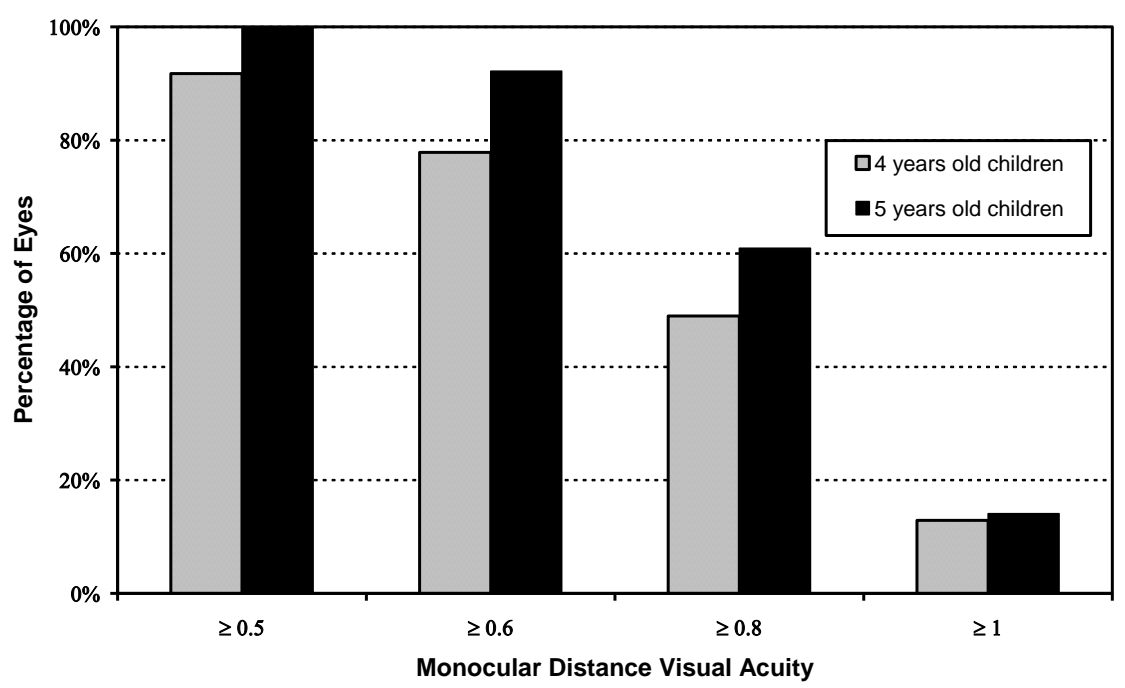

Fig. 3. Accumulative distribution for monocular distance visual acuity.

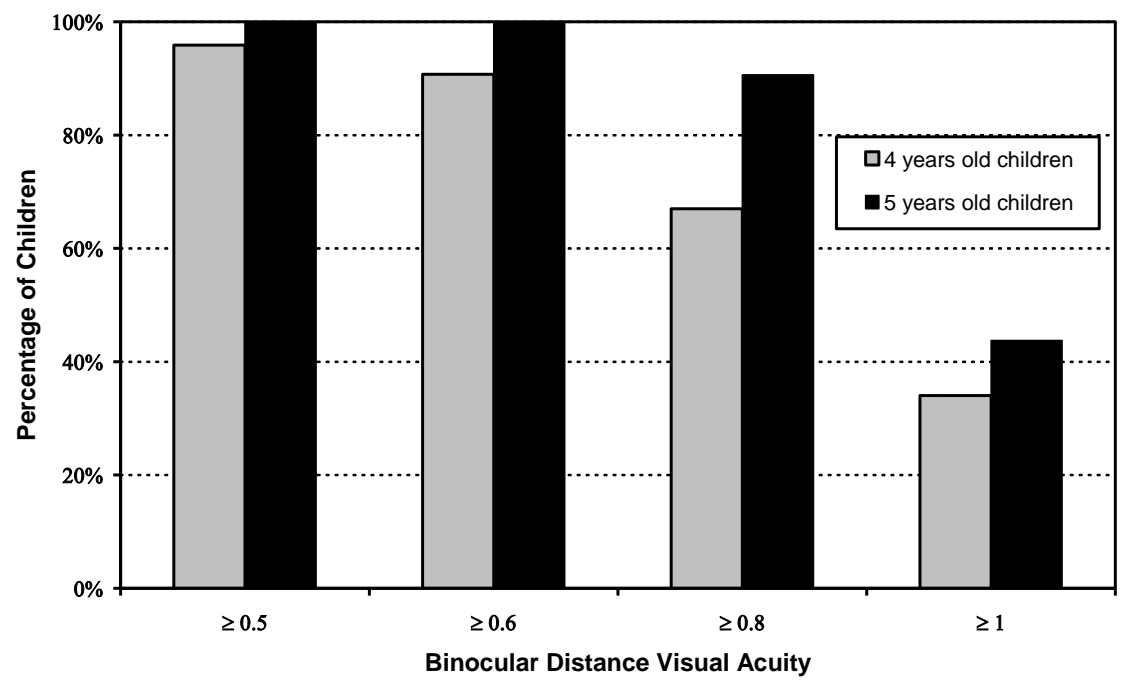

Fig. 4. Accumulative distribution for binocular distance visual acuity.

\subsection{Retinoscopy}

It was performed in free space by using skiascopy lenses (in 0.50 D steps) without cycloplegic and with the child's fixation maintained at a distance target. An eye was considered emmetropic provided that a refraction value from $-0.50 \mathrm{D}$ to $+0.50 \mathrm{D}$ was found. However, the criterion to referral was hyperopia $>+1.00 \mathrm{D}$ or myopia $<-0.50 \mathrm{D}$ in any principal meridians. The refraction values were statistically analyzed in function of gender and age. As it was expected, appreciable changes were only found in function of the age of the children. The statistical distribution of myopic, emmetropic, and hyperopic eyes and children are shown in Figs. 5 and 6 . These results show that, when the children grow up, the probability of being emmetropic increase.

\subsection{Cover testing for near}

An accommodative target was used and the child had to look at 0.60 VA letters. Any tropia, endophoria or hyperphoria was criterion to refer but only exophoria higher than $10 \Delta$ was referred. Only two tropias were found in our screening (1.6\% of the preschoolers) and both were referred to the ophthalmologist.

\subsection{Stereoscopic acuity}

It was valued by means of the Titmus-Wirt test, which requires that the child is wearing polarized glasses. Usually, if stereoacuity is 40 " 


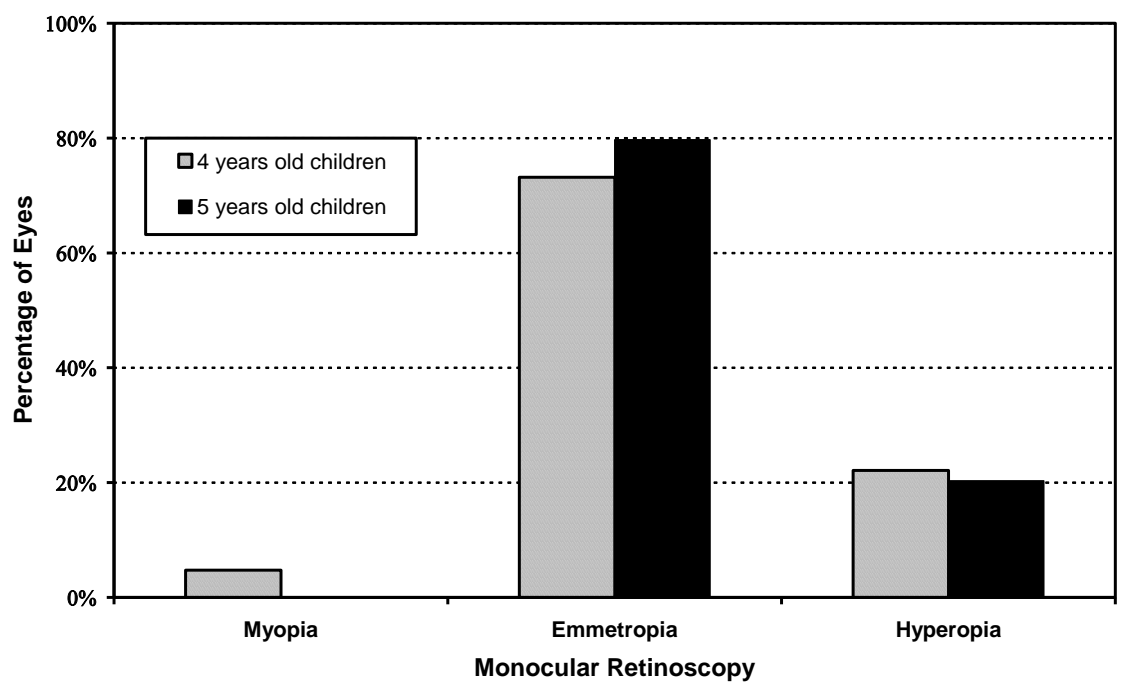

Fig. 5. Statistical distribution of monocular retinoscopy.

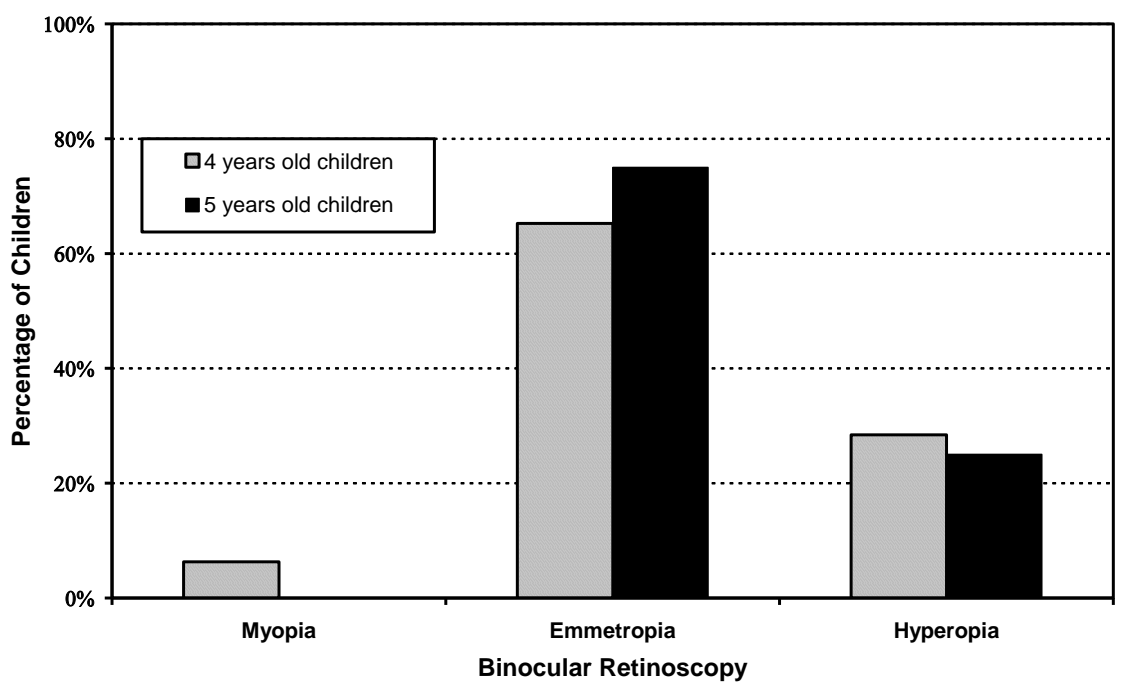

Fig. 6. Statistical distribution of binocular retinoscopy.

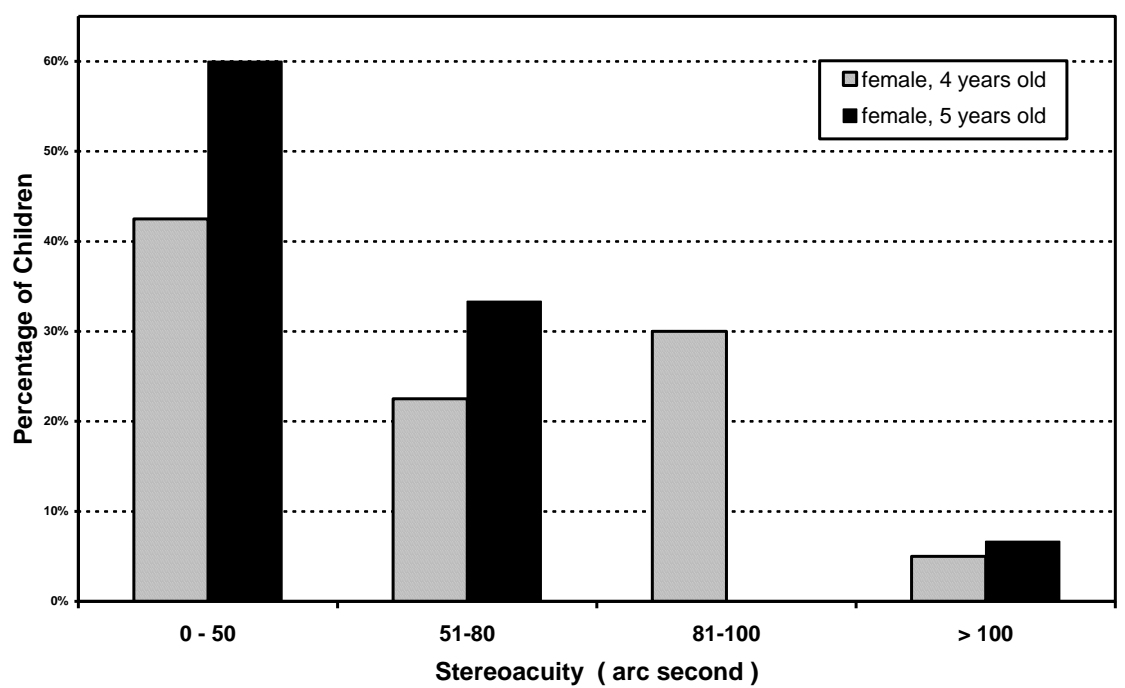

Fig. 7. Statistical distribution of stereoacuity for female children. 


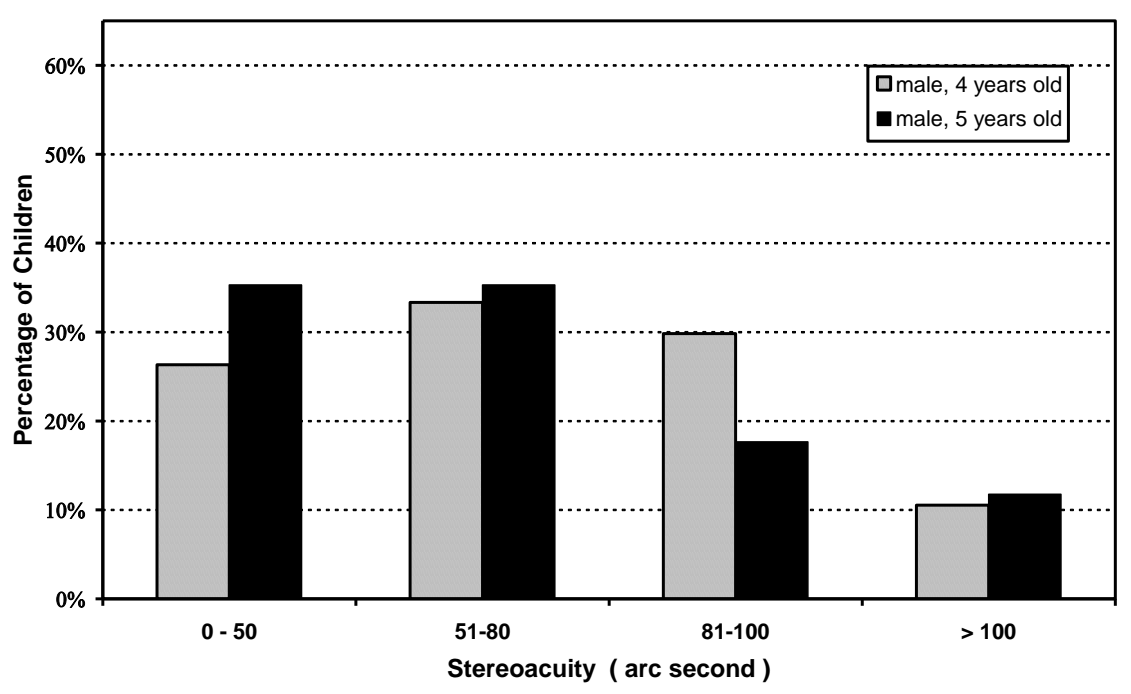

Fig. 8. Statistical distribution of stereoacuity for male children.

or better, the test is passed. However, this value can not be taken as only criterion to refer, due to the children is still growing up. In fact, stereoacuity results demonstrate that there are clear differences depending on gender and on age as it was previously reported [22,23]. Statistical distributions of stereoacuity for female and male children are shown in Figs. 7 and 8. To analyze the temporary evolution of stereoacuity, four main categories have been considered: 0-50", 51"-80", 81"-100" and $>100$ ".In fact, males are homogeneously distributed between the four categories (stereoacuity up to 100") and there is only a slight improvement in 5 years old males. However, although females are also distributed between the four categories, a $43 \%$ of 4 years old females and a $60 \%$ of females aged 5 have a stereoacuity better than 50". Additionally, all of the older females have a stereoacuity better than 80 ", except a tropia. Therefore, their stereopsis has clearly improved, but it is still in progress. Finally, taking into account these results, younger children and males aged 5 would pass the test with values better than 100" whereas 5 years old females should obtain values better than 80". The two children with tropia founded with cover-test had $>100$ " stereopsis.

\subsection{Ocular motility}

Comitant, pursuit, and saccadic movements with non-accommodative stimulus were examined. Pursuit movements are conjugate eye movements which smoothly track slowly moving objects in the visual field and saccadic movements are very fast jumps from one eye position to another. Noncomitant eye movements or motility restriction were considered abnormal. Noncomitant ocular movement was found in one child $(0.8 \%)$ and limitation in the pursuit and saccadic movements was observed in other one $(0.8 \%)$. Both children were advised to ask for an ophthalmologist opinion.

\subsection{Near point of convergence}

This distance defines the amplitude of convergence or the closest point in space where the patient can hold fusion, and therefore, see one object. Because few recent studies provided data for preschoolers, normal values were $6 / 10$ $\mathrm{cm}$ for this point and for the recovery [24-26]. The principal concentration of our values is in the $0-5 \mathrm{~cm}$ range, $95 \%$ and $93 \%$ of the children had NPC break and recovery values $<5 \mathrm{~cm}$ respectively. Based on these results, $5 \mathrm{~cm}$ NPC break/recovery could be a predictor of possible convergence dysfunctions for 4-5 years old children.

\subsection{Near Worth four dots}

It was performed to test the suppression of one eye or double vision. The patient is wearing anaglyphic glasses while is asked about the number and the color of the four dots at $40 \mathrm{~cm}$. Four dots is the only correct answer and any 
other response was considered cause of referral. This test was passed by all of children.

\subsection{Color vision}

Ishihara color testing was performed. Failure was defined as defects consistent with the answer key provided by the test manufacturer. All of children passed this test. This fact is compatible with the results reported by other authors. In Bodack et al. [6], only 7 (0.4\%) of 1795 children failed this test. Assuming that the probability of failure of this test was approximately $0.4 \%$, the probability that this test was passed by all children of the 127 screened is a $60 \%$.

\subsection{Vision screening and referral criteria}

To decide what children have to be referred to the ophthalmologist because they need a more comprehensive ophthalmic examination it is necessary to establish a suitable protocol. In our case, this protocol depends mainly on two tests: distance VA and retinoscopy. However, the two tests must be considered together, since neither a good VA guarantees emmetropia (for instance, hyperopic children exhibit high VA) nor a right retinoscopy ensures the lack of visual defects (for example, anisometropic children) [6]. Nevertheless, VA is considered the main criterion because skiascopy lenses are arranged in $0.50 \mathrm{D}$ steps and, moreover, the child can change its fixation distance. Retinoscopy without using cyclopegic is quite difficult for children because of their high accommodation amplitude. Finally, VA values in the limit do not necessarily imply any visual defect, since the child's eyes are still growing up.

Therefore, it is advisable that a child is referred to the ophthalmologist in the following cases, since it seems clear that the child has some visual problem:

1) Anisometropia or low VA, although the retinoscopy test could be right. Of course, children with quite high myopia have usually these defects.

2) High hyperopia $(>+1.0$ D), although normal values of VA could be reached by the child.
Moreover, it is advisable that a child is periodically monitored in the following other cases:

3) VA in the limit of normal values provided that the child have not been referred due to high hyperopia or myopia.

4) Slight myopia (>-0.5 D), as a preventive measure although the child has normal VA.

A breakdown of cases by specific test item is compared with the number of children who received the test (Table I). Of the 127 children screened in this study, 78 (61\%) passed, but only $21(17 \%)$ were referred. Nevertheless, 28 (22\%) will be annually monitoring and they could be referred later. On the other hand, 4 children more were referred: 2 of them failed the cover test and other 2 presented some problem of ocular motility.

Of the 25 children who could be referred 6 of them were wearing spectacles at the time of the screening. If a child was wearing glasses at the time of the screening, all tests, excluding retinoscopy, were done over the glasses. Wearing glasses, no children failed the screening. To summarize, 19 children who had abnormal vision required corrective lenses or a wider ophthalmological exploration. This evaluation supports the importance of school optometric vision screening programs because $15 \%$ of the screened children needed further revisions.

\section{Discussion}

Regarding educational rate of attainment, visual difficulties are a strong educational disadvantage. For instance, reading difficulties are commonly associated with disorders of visual function. In a group of children these visual difficulties may go unnoticed unless a comprehensive visual assessment is performed. Usually, low binocular VA can be unperceived if one of the eyes has normal or high monocular VA.

Unfortunately, a comprehensive assessment uses to be very long and it addresses a full range of ocular factors so that highly trained personnel 
Table I

Results of the protocol applied to decide what children had to be referred to the ophthalmologist.

\begin{tabular}{|c|c|c|c|c|c|c|c|c|}
\hline \multirow{2}{*}{$\begin{array}{l}\text { Distance VA } \\
\mathrm{OK}\end{array}$} & \multirow{2}{*}{ Retinoscopy } & \multirow{2}{*}{$\begin{aligned} \text { Action } \\
\text { PASS }\end{aligned}$} & \multicolumn{2}{|c|}{4 years old } & \multicolumn{2}{|c|}{5 years old } & \multicolumn{2}{|c|}{ Total } \\
\hline & & & 14 & $44 \%$ & 49 & $52 \%$ & 63 & $50 \%$ \\
\hline $\mathrm{OK}$ & HYPERMETROPIA < +1 D & PASS & 3 & $9 \%$ & 12 & $13 \%$ & 15 & $12 \%$ \\
\hline $\mathrm{OK}$ & HYPERMETROPIA > +1 D & REFER & & & 7 & $7 \%$ & 7 & $6 \%$ \\
\hline $\mathrm{OK}$ & MYOPIA & MONITOR & & & 1 & $1 \%$ & 1 & $1 \%$ \\
\hline LIMIT & $\mathrm{OK}$ & MONITOR & 10 & $31 \%$ & 10 & $11 \%$ & 20 & $16 \%$ \\
\hline LIMIT & HYPERMETROPIA < +1 D & MONITOR & 2 & $6 \%$ & 4 & $4 \%$ & 6 & $5 \%$ \\
\hline LIMIT & HYPERMETROPIA > +1 D & REFER & 3 & $9 \%$ & 1 & $1 \%$ & 4 & $3 \%$ \\
\hline LIMIT & MYOPIA & MONITOR & & & 1 & $1 \%$ & 1 & $1 \%$ \\
\hline LOW & & REFER & & & 2 & $2 \%$ & 2 & $2 \%$ \\
\hline ANISOMETROPIA & & REFER & & & 8 & $8 \%$ & 8 & $6 \%$ \\
\hline & & PASS & 17 & $53 \%$ & 61 & $64 \%$ & 78 & $61 \%$ \\
\hline & & MONITOR & 12 & $38 \%$ & 16 & $17 \%$ & 28 & $22 \%$ \\
\hline & & REFER & 3 & $9 \%$ & 18 & $19 \%$ & 21 & $17 \%$ \\
\hline
\end{tabular}

are required [19]. To avoid these problems, we propose to find an easy and fast battery of tests but highly reliable by an optometrist. Although several authors [27-29] indicate the importance of high-quality school-based vision screening programs, results of the accuracy of referrals are diverse $[17,18]$ and the reliability of the screening diminishes. In fact, in several countries screening tests can be administered by school nurses, orthoptists, optometrists and ophthalmologist varying widely in performance and in results [30-34].

Our study tries to obtain reference normal values and contributes to clarify the incidence and prevalence of various vision problems among youth. Although its validity can be limited since the population screened was only urban Caucasian children, the design of the optometric screening and findings from this evaluation may be generalized to other communities.

The patient population in this study was made up of preschool (4 and 5 years old)
Caucasian students in an urban area. A lower failure rate of the test might be expected because these children were screening by pediatricians at four years old and should have been treated for VA problems. However, screening based only on VA may miss those children with hyperopia, binocular disorders or other ocular health problems. As it is reported by other authors, the success of a vision screening is due, in part, to its design. Visual risk factors in preschool children should be considered [35] as well as the implication in visual impairment in these children [36]. Providers of vision screening programs should be cognizant of the accurate of each test used [37] and the associations between refractive errors and binocular disorders [3841]. In fact, our results suggest that retinoscopy (objective test) is necessary when the VA test (subjective test) is performed; the reason is that retinoscopy detects all types of ammetropy, even in the presence of passing distance acuity tests. In our screening, 21 children were referred, but only 10 children would have been referred if 
retinoscopy results had not been taken into account.

Obviously, undetected binocular disorders should be also identified during the screening. It is important to determine what tests are more suitable. Thus, all the children should do some stereopsis test (Titmus-Wirt, for example), but their results must be valued depending on their age, since in this study a clear relationship between cutoff values of stereopsis and the age of the child has been found. On the other hand, perhaps the least effective exam of the proposed screening was the near Worth four dots test. In our study, the two children with detected tropia by cover-test had fusion with Worth. Stereopsis test evaluates the third level of the binocular vision, since to have good stereopsis simultaneous perception and fusion of the stimuli are needed. Worth will be a useful exam when stereopsis is limited and this test should be only performed by these children.

Our proposal to design a vision screening is to perform, at least, all the examinations that we have been presented but the collaboration of the children could determine the duration of the explorations or the sessions needed to finish the evaluation.

A limitation of this study was that the data is representative of only one year period. Prevalence of refractive errors or ocular abnormalities can vary over time and a longitudinal approach may provide a better perspective. Currently, the inability to follow-up the referral after screening and the impossibility to know how many healthy children (falsepositive rate) were referred must be considered. Unfortunately, we were unable to assess the false-negative rate either. This point could be resolved if this program is annually repeated and the children who don't pass the screening one time could be followed-up in their own school. Additionally, the sample did not include any information on anamnesis or environmental factors that may influence on child ocular health. Subsequent analyses, based on wider population as well as results over the time will address these issues.
In conclusion, the prevalence of undetected vision problems in preschool children has been clearly demonstrated. Vision screening programs in schools are highly recommended. Nevertheless, coordination among professionals conducting screening, school personnel and parents are needed to reach high levels of success. The results of this study validate an easy and fast battery of tests. The vision screening has been highly reliable because reference normal values have been defined by analyzing statistically the results of these tests.

Vision screening is considered to be an important part of a strategy to improve both VA and visual efficiency because inefficiencies in the visual system affect academic achievement. Accommodative and binocular dysfunctions can have a negative impact on learning, particularly as visual demand increases in higher grades when print is smaller and reading requirements are greater. There is a need to inform school personnel and parents about basic visual health and how detect small indications of ocular disorders. The results of this work provide information on the prevalence of ocular conditions among preschool children, which can be useful for the schools interested in improving visual health. Any school attempting to initiate visual prevention programs can incorporate strategies based on these results.

\section{Acknowledgements}

The authors would like to thank to the staff of the CEIP Doctor Azúa and the CEIP Ana Mayayo for their technical support and collaboration in this research.

Disclosure of funding sources. This research received no specific grant from any funding agency in the public, commercial, or not-forprofit sectors.

Disclosure of potential conflict of interest. The authors report no conflicts of interest and have no proprietary interest in any of the materials mentioned in this article. 